\title{
Perancangan Fasilitas dan Layout untuk Menjual Sayur Menggunakan Triseda
}

\section{Design of Facilities and Layout to Sell Vegetables Using Triseda}

\author{
Yoshua Glenn Winston, Elty Sarvia \\ Jurusan Teknik Industri, Fakultas Teknik, Universitas Kristen Maranatha Jl. Prof.drg.Soeria Soemantri No. \\ 65. Bandung 40164 - Jawa Barat \\ E-mail: glennyoshua@gmail.com, elty.sarvia@eng.maranatha.edu
}

\begin{abstract}
ABSTRAK
Pasar tradisional dan pasar modern tidak selalu ada didekat pemukiman penduduk. Sehingga, masyarakat yang tinggal di dalam perumahan sulit mendapatkan sayuran, daging, dan ikan segar serta bumbu masakan lainnya. hasil wawancara dari penjual sayur keliling ingin merubah kendaraan yang digunakan dalam berjualan dengan menggunakan Triseda. ini dikarenakan barang dagangannya yang dibawa menggunakan gerobak saat ini masih terbatas penyimpanannya, tidak dapat menahan hujan, belum tersedianya lemari pendingin, dan jangkauan pelanggan masih terbatas. tujuan penelitian ini adalah untuk mengusulkan fasilitas fisik yang ergonomis dengan mengusulkan rancangan layout kabin triseda, penataan sayur mayur, keamanan barang, dan rancangan fasilitas listrik untuk lemari pendingin. Perancangan dimulai dengan analisis data antropometri untuk rancangan fasilitas fisik yang terdiri dari rak sayur, bumbu, bawang, dan meja penjual. Kemudian, Penelitian ini mendapatkan alternatif layout 2 berdasarkan concept scoring. Penerapan metode 5S yaitu melakukan pemilahan barang yang dibutuhkan, menyediakan tempat khusus untuk penyimpanan, rancangan rak yang mudah dibersihkan, menjaga kondisi kerja dengan membersihkan barang yang telah dipakai, dan berkomitmen agar tetap melakukan metode 5S. Pada keamanan barang terdiri dari bak triseda yang diberikan pengunci, barang disimpan pada tempat ideal, bahan makanan berbau amis dibungkus menggunakan polystren sehingga barang yang dibawa oleh penjual menjadi aman.
\end{abstract}

Kata kunci: Antropometri, Concept Scoring, 5S, Sayur. Layout,

\begin{abstract}
Traditional markets and modern markets do not always exist near residential areas. Thus, it is difficult for people living in the housing complex to get fresh vegetables, meat, fish and other cooking spices. the result of an interview from a mobile vegetable seller who wants to change the vehicle used in selling by using Triseda. This is because the merchandise that is carried by cart is currently still limited in storage, unable to withstand the rain, not available refrigerators, and the reach of customers is still limited. The purpose of this study is to propose an ergonomic physical facility by proposing the layout of the triseda cabin, vegetable arrangement, safety of goods, and the design of electrical facilities for refrigerators. The design begins with analyzing anthropometric data for the design of physical facilities consisting of shelves for vegetables, spices, onions, and a seller's table. Then, this study gets 2 alternative layouts based on concept scoring. The application of the $5 S$ method is to sort the items needed, provide a special place for storage, design a shelf that is easy to clean, maintain working conditions by cleaning items that have been used, and commit to continue using the $5 S$ method. The security of goods consists of a triseda tub that is given a lock, goods are stored in an ideal place, fishy-smelling foodstuffs are wrapped using polystren so that the goods carried by the seller are safe.
\end{abstract}

Keywords: Anthropometric, Concept Scoring, 5S, Vegetable, Layout 


\section{Pendahuluan}

Manusia dalam kehidupannya banyak menggunakan desain sebagai fasilitas penunjang aktivitasnya. Manusia menginginkan desain produk yang sesuai dengan trend dan mewadahi kebutuhannya yang semakin meningkat. Selain itu, aktivitas desain produk yang menghasilkan gagasan kreatif dipengaruhi pula oleh kecepatan membaca situasi, khususnya kebutuhan pasar dan permintaan pembeli. Untuk menilai suatu hasil akhir dari produk sebagai kategori nilai desain yang baik biasanya ada tiga unsur yang mendasari, yaitu fungsional, estetika, dan ekonomi. Kriteria pemilihannya adalah function and purpose, utility and economic, form and style, image and meaning. Unsur fungsional dan estetika sering disebut fit-formfunction, sedangkan unsur ekonomi lebih dipengaruhi oleh harga dan kemampuan daya beli masyarakat. Fokus perhatian dari sebuah kajian ergonomis akan mengarah ke upaya pencapaian sebuah perancangan desain suatu produk yang memenuhi persyaratan 'fitting the task to the man' sehingga setiap rancangan desain harus selalu memikirkan kepentingan manusia, yakni perihal keselamatan, kesehatan, keamanan maupun kenyamanan (Rosnani, 2010).

Kebutuhan manusia akan makanan diperoleh dari berbagai sumber nabati maupun hewan. Pada dasarnya makanan merupakan campuran senyawa kimia, yang dapat dikelompokkan ke dalam karbohidrat, lemak, protein, vitamin, mineral dan air (Effendi, 2012). Masyarakat biasanya membeli kebutuhan pokoknya seperti sayur-sayuran, ikan, daging, dan bumbu masak lainnya di pasar tradisional ataupun di pasar modern. Akan tetapi, pasar tradisional dan pasar modern tidak selalu ada didekat pemukiman penduduk, hal ini akan menyulitkan masyarakat untuk mendapatkan sayuran segar, daging segar, ikan segar, dan bumbu masakan lainnya. Masyarakat juga terkadang enggan untuk datang langsung ke pasar tradisional ataupun pasar modern karena dibatasi oleh jarak yang jauh dan akan memakan waktu yang lama juga untuk dapat mencapai pasar yang sedang dituju. Kadangkala juga saat berbelanja ke pasar, masyarakat harus berdesak-desakan dan tidak menutup kemungkinan terjadi aksi pencopetan yang dapat merugikan pengunjung pasar.

Saat ini, sudah cukup banyak sekali penjual sayur-sayuran yang menjual barang dagangannya dengan lesehan maupun dengan berkeliling menggunakan gerobak dan sepeda motor. Akan tetapi, biasanya tempat berjualannya tidak dapat menahan sinar matahari maupun hujan sehingga membuat barang yang dijualnya cepat layu, rusak, dan terlihat tidak fresh. Para penjual yang menggunakan gerobak dan sepeda motor juga tidak dapat membawa dagangan yang banyak dan beraneka ragam sesuai kebutuhan dari masyarakat akibat dari tempat penyimpanan barang yang sangat terbatas. Maka dari itu, akan dirancangnya tempat jualan bagi penjual sayur keliling dengan memakai motor roda tiga yang dapat mengangkut lebih banyak macam kebutuhan pokok dari masyarakat dengan mempertahankan juga kesegaran dari sayuran, daging, ikan, dan bumbu masak lainnya hingga sampai ditangan pembeli serta dengan digunakan motor roda tiga ini tidak akan memakan banyak ruas jalan karena dimensi dari kendaraan yang digunakan ramping. Perancangan ini juga melibatkan dalam aspek K3 dalam proses perancangannya dan metode $5 \mathrm{~S}$ penataannya.

\section{Metode Penelitian}

Tahapan penelitian dimulai dari peneltian pendahuluan, dimana penulis melakukan observasi dan wawancara kepada pihak pedagang untuk menanyakan masalah yang terjadi pada tempat berjualanya saat ini. Pihak pedagang yang diwawancarai adalah hanya satu orang, dimana pedagang tersebut yang memiliki jumlah macam barang lebih lengkap dibandingkan dengan pedagang lain dan memiliki kebutuhan untuk perancangan ini. Setelah dilakukan wawancara dan observasi kemudian didapatkan masalah seperti yang telah dijabarkan pada pendahuluan sebelumnya, kemudian membuat pembatasan dan asumsi supaya penelitian yang akan dilakukan oleh penulis menjadi lebih terarah dan mudah.

Pengumpulan data yang diperlukan untuk penelitian seperti data spesifikasi motor roda tiga yang digunakan dalam proses perancangan alat- alat fasilitas yang digunakan agar tidak melebihi dari ukuran maksimum dari dimensi kendaraan yang digunakan; daftar nama barang yang dijual, karakteristik, dan pengelompokan; spesifikasi barang yang dijual; daftar alat fasilitas fisik yang akan digunakan; job description dari pengguna/penjual. Peneliti melakukan perancangan dan pengolahan data akan dimulai dari proses menganalisis rancangan triseda awal menggunakan data antopometri; penentuan spesifikasi data fasilitas fisik dan melakukan perancangan fasilitas fisik menggunakan data antropometri manusia, data acuan lainnya, dan penetapan persentil; 
penentuan kriteria concept scoring produk fasilitas fisik, penentuan kriteria concept scoring alternatif layout; analisis penerapan metode $5 \mathrm{~S}$ pada rancangan triseda; analisis keamanan dan keselamatan. Metode concept scoring digunakan memilih produk terbaik berdasarkan kriteria yang telah ditetapkan, dan metode 5S supaya dapat mewujudkan lingkungan yang nyaman.

\section{Hasil dan Pembahasan}

Rancangan awal triseda clearance bak kendaraan dari dibandingkan dengan data antropometri tinggi genggaman tangan pada posisi relaks ke bawah wanita persentil 5\% ukuran $646 \mathrm{~mm}$, bahwa ukuran dari dasar bak kendaraan triseda yang memiliki tinggi ground clearance sebesar $700 \mathrm{~mm}$ masih dapat dijangkau dengan nyaman bagi pembeli yang memiliki postur tubuh rendah. Sehingga barang yang ada didasar bak triseda masih dapat dijangkau dengan nyaman karena ukuran tinggi bak kendaraan lebih tinggi dari pembeli yang memiliki tinggi genggaman tangan pada posisi relaks ke bawah wanita persentil 5\%. Serta bagi pembeli yang memiliki tinggi genggaman tangan pada posisi relaks ke bawah wanita persentil 50\% dengan ukuran $708 \mathrm{~mm}$ masih tetap dapat dengan nyaman mengambil barang yang ada pada dasar bak yang memiliki ground clearance $700 \mathrm{~mm}$ karena ukurannya pas sehingga saat sedang mengambil barang, pembeli yang memiliki tinggi genggaman tangan pada posisi relaks ke bawah persentil $5 \%$ maupun $50 \%$ (tidak perlu untuk membungkukkan badan supaya dapat menjangkau barang yang ada pada dasar bak. Sehingga dapat disimpulkan triseda ini layak untuk digunakan untuk kegiatan penjualan sayur mayur.

\section{Perancangan Fasilitas Fisik Rancangan}

Perancangan fasilitas fisik berdasarkan data antropometri dan data acuan lainnya (Nurmianto, 2004). Dikarenakan perancangan yang dirancang memiliki layout yang terbatas. Fasilitas fisik yang dirancang harus juga memperhatikan fasilitas fisik lainnya supaya tetap bisa masuk kedalam bak kabin kendaraan yang digunakan. Berikut adalah penentuan data antropometri dan perancangan untuk fasilitas fisik. Pada perancangan fasilitas fisik terdapat keterbatasan sehingga hanya menampilkan satu tabel antropometri saja yaitu data antropometri untuk perancangan rak sayur . Didalam perancangan, terdapat tiga altenatif yang didalam perancangannya menggunakan data antropometri sebagai acuan dalam perancangan fasilitas fisik sehingga fasilitas yang dirancang sesuai dengan kebutuhan penggunanya.

Tabel 1. Penentuan data antropometri dan acuan lainnya untuk perancangan rak sayur

\begin{tabular}{|c|c|c|c|c|c|c|c|c|c|}
\hline \multicolumn{2}{|l|}{ Dimensi } & \multirow{2}{*}{\begin{tabular}{|c|} 
Data Antropometri Atas Acuan Lainnya \\
Lebar Bahu (bideltoid)
\end{tabular}} & \multirow{2}{*}{\begin{tabular}{|c|} 
Persentil \\
$5 \%$
\end{tabular}} & \multirow{2}{*}{$\begin{array}{c}\text { Jenis } \\
\text { Kelamin }\end{array}$} & \multirow{2}{*}{$\begin{array}{c}\text { Ukuran (mm) } \\
-\end{array}$} & \multirow{2}{*}{$\begin{array}{c}\text { Allowance } \\
\text { (mm) }\end{array}$} & \multirow{2}{*}{$\begin{array}{c}\begin{array}{c}\text { Ukuran } \\
(\mathrm{mm})\end{array} \\
342\end{array}$} & \multirow{3}{*}{$\begin{array}{c}\begin{array}{c}\text { Ukuran } \\
\text { Yang } \\
\text { Disarankan } \\
\text { (mm) }\end{array} \\
342-1.400\end{array}$} & \multirow{3}{*}{$\begin{array}{c}\begin{array}{c}\text { Terpilih } \\
\text { (mm) }\end{array} \\
900 \mathrm{~mm}\end{array}$} \\
\hline Panjang & Min & & & & & & & & \\
\hline Rak Sayur & $\operatorname{Max}$ & $\begin{array}{c}\text { Jarak Bentang dari Ujung Jari Tangan } \\
\text { Kiri ke Kanan }\end{array}$ & $5 \%$ & Wanita & - & - & 1.400 & & \\
\hline \multirow{2}{*}{$\begin{array}{l}\text { Lebar Rak } \\
\text { Sayur }\end{array}$} & Min & Dimensi Sayur Maksimun Yang Dijual & - & - & - & - & 200 & \multirow[b]{2}{*}{$200-610$} & \multirow[b]{2}{*}{$400 \mathrm{~mm}$} \\
\hline & $\operatorname{Max}$ & \begin{tabular}{|c|} 
Jarak Genggaman Tangan (grip) ke \\
Punggung pada Posisi Tangan ke Depan \\
(horisontal) \\
\end{tabular} & $5 \%$ & Wanita & - & - & 610 & & \\
\hline \multirow{2}{*}{$\begin{array}{c}\text { Tinggi Rak } \\
\text { Sayur }\end{array}$} & Min & $\begin{array}{c}\text { Tinggi Mata Berdiri - Tinggi Bak Kabin } \\
\text { Dari Tanah } \\
\end{array}$ & $50 \%$ & Wanita & $\begin{array}{c}1.446-700= \\
746\end{array}$ & - & 746 & \multirow{2}{*}{$746-842$} & \multirow{2}{*}{$840 \mathrm{~mm}$} \\
\hline & $\operatorname{Max}$ & $\begin{array}{c}\text { Tinggi Mata Berdiri - Tinggi Bak Kabin } \\
\text { Dari Tanah }\end{array}$ & $95 \%$ & Wanita & $\begin{array}{c}1.542-700= \\
842\end{array}$ & - & 842 & & \\
\hline \multirow{2}{*}{$\begin{array}{l}\text { Panjang } \\
\text { Keranjang } \\
\text { Di Dalam } \\
\text { Rak } \\
\end{array}$} & Min & Dimensi Sayur Maksimun Yang Dijual & - & - & - & - & 200 & \multirow{2}{*}{$200-1.400$} & \multirow{2}{*}{$270 \mathrm{~mm}$} \\
\hline & $\operatorname{Max}$ & $\begin{array}{c}\text { Jarak Bentang dari Ujung Jari Tangan } \\
\text { Kiri ke Kanan } \\
\end{array}$ & $5 \%$ & Wanita & - & - & 1.400 & & \\
\hline \multirow{2}{*}{$\begin{array}{c}\text { Lebar } \\
\text { Keranjang } \\
\text { Di Dalam } \\
\text { Rak }\end{array}$} & Min & Dimensi Sayur Maksimun Yang Dijual & - & - & - & - & 200 & \multirow[b]{2}{*}{$200-610$} & \multirow[b]{2}{*}{$380 \mathrm{~mm}$} \\
\hline & $\operatorname{Max}$ & \begin{tabular}{|c|} 
Jarak Genggaman Tangan (grip) ke \\
Punggung pada Posisi Tangan ke Depan \\
(horisontal)
\end{tabular} & $5 \%$ & Wanita & - & - & 610 & & \\
\hline \multirow{2}{*}{$\begin{array}{l}\text { Tinggi } \\
\text { Keranjang } \\
\text { Di Dalam } \\
\text { Rak }\end{array}$} & Min & Dimensi Sayur Maksimun Yang Dijual & - & - & - & - & 150 & \multirow{2}{*}{$150-281$} & \multirow{2}{*}{$250 \mathrm{~mm}$} \\
\hline & $\operatorname{Max}$ & Max Tinggi Rak Sayur x 1/3 & - & - & $\begin{array}{c}840 \times 1 / 3= \\
281\end{array}$ & - & 281 & & \\
\hline \multirow{2}{*}{$\begin{array}{c}\text { Tinggi } \\
\text { Tiang } \\
\text { Penyangga }\end{array}$} & Min & \multirow{2}{*}{$\begin{array}{l}\text { Tinggi Tubuh Posisi Berdiri Tegak - } \\
\text { Tinggi Rak - Ground Clearance }\end{array}$} & \multirow{2}{*}{$95 \%$} & \multirow{2}{*}{ Pria } & \multirow{2}{*}{$\begin{array}{c}1.732-840- \\
700=192\end{array}$} & \multirow{2}{*}{118} & \multirow{2}{*}{310} & \multirow{2}{*}{310} & \multirow{2}{*}{$310 \mathrm{~mm}$} \\
\hline & $\operatorname{Max}$ & & & & & & & & \\
\hline
\end{tabular}


Pada perancangan rak bumbu, panjang rak menggunakan nilai $350 \mathrm{~mm}$ karena harus memperhatikan panjang kaabin kendaraan dan jarak bentang penggunanya. Pada lebar rak menggunakan nilai $400 \mathrm{~mm}$ dengan memperhatikan lebar kaabin daaan jarak maksimum genggaman tangan sehingga pemgguna dapat menjangkau barang yang ada pad arak bumbu. Pada tinggi rak menggunakan data nilai $840 \mathrm{~mm}$ yang telah disesuaikan dengan tinggi mata berdiri supaya pengguna tetap dapat tetap melihat barang yang berada paling atas rak tersebut. Pada panjang keranjang menggunakan nilai $350 \mathrm{~mm}$ dengan telah memperhatikan dimensi dari bumbu yang akan ditata itu sendiri dan jarak bentangan tangan pengguna. Pada lebar keranjang menggunakan nilai $380 \mathrm{~mm}$ dengan memperhatikan jarak genggaman tangan sehingga pengguna dapat mengjangkau barang yang berada di sisi kanan atau belakang rak, yaitu dimensi.

Sedangkan tinggi keranjang menggunakan nilai $200 \mathrm{~mm}$ dengan memperahatikan masksimum tinggi jumlah rak yang akan dirancang sehingga dari total tinggi dibagi dengan jumlah tingkatan rak. Sedangkan panjang pembatas menggunakan data panjang keranjang yaitu $350 \mathrm{~mm}$ dan pembatas menggunakan data 1/4 tinggi level yaitu $50 \mathrm{~mm}$.

Pada perancangan rak bawang, panjang rak menggunakan niali $350 \mathrm{~mm}$ karena harus memperhatikan kabin kendaraan yang dipakai supaya fasilitas yang dirancang dapat masuk ke dalam kabin dan meperhatikan juga jarak bentang tangan manusia agar rak yang dirancang tidak terlalu lebar. Pada lebar rak bawang menggunakan nilai $400 \mathrm{~mm}$ yang telah memperhatikan lebar kabin dan jarak genggaman tangan ke depan sehingga pengguna dapat menjangkau barang yang ada di dalam rak. Pada tinggi rak menggunakan nilai $840 \mathrm{~mm}$ dengan memperhatikan tinggi mata berdiri supaya pengguna dapat dengan nyaman saat akan melihat barang yang ada di dalam rak bawang. Pada panjang keranjang menggunakan nilai $300 \mathrm{~mm}$ dengan memperhatikan dimensi bawang maksimum yang akan ditempatkan pad arak dan jarak bentangan tangan penggunanya. Pada lebar keranjang menggunakan nilai $380 \mathrm{~mm}$ yang telah memperhatikan dimensi jarak genggaman tangan ke depan dan dimensi maksimum bawang. Pada tinggi keranjang menggunakan nilai $180 \mathrm{~mm}$ karena dalam perancangan harus memperhatikan dimensi bawang dan maksimum tinggi dari yang digunakan. Pada perancangan panjang handle menggunakan nilai $78 \mathrm{~mm}$ dengan memperhatikan lebar telapak tangan sehingga pengguna dapat menggunakan handle dengan mudah. Sedangkan pada perancangan lebar handle menggunakan nilai $29 \mathrm{~mm}$ dengan memperhatikan tebal telapak tangan pengguna sehingga pengguna dapat menggunakan handle dengan mudah.

Pada perancangan meja, panjang meja menggunakan nilai $615 \mathrm{~mm}$ yang telah memperhatikan perlengkapan yang akan dipakai dan jarak bentangan tangan ke samping sehingga pengguna dapat dengan mudah dalam bekerja. Pada lebar meja menggunakan nilai $400 \mathrm{~mm}$, ukuran ini telah dipertimbangkan dengan lebar peralatan yang akan ditempatkan pada atas meja dan jarak bentangan tangan ke samping. Pada tinggi meja menggunakan nilai $315 \mathrm{~mm}$ yang telah disesuaikan dengan tinggi bak kabin dan tinggi siku penjual sehingga penjual tidak merasa terganggu saat melayani konsumen. Pada panjang laci meja menggunakan nilai $575 \mathrm{~mm}$, ukuran ini didapat untuk dapat memaksimalkan barang yang akan dimasukkan ke dalam laci yang akan digunakan. Pada lebar laci meja menggunakan nilai $287.5 \mathrm{~mm}$ yang telah disesuikan dengan bagian penyangga pada kiri dan kanan serta tinggi meja menggunakan nilai $100 \mathrm{~mm}$ karena memperhatikan peralatan yang akan dimasukkan ke dalam laci supaya peralatan tersebut dapat masuk dengan mudah dan baik. Pada perancangan panjang handle menggunakan data lebar jari telunjuk dan data lebar telapak tangan sehingga ukuran yang dipakai dalam perancangan adalah $88 \mathrm{~mm}$. Sedangkan lebar handle menggunakan data tebal jari telunjuk dan data tebal telapak tangan sehingga ukuran yang dipakai dalam perancangan adalah $34 \mathrm{~mm}$.

\section{Fasilitas Fisik Pembanding 1}

Perancangan fasilitas fisik pembanding didapatkan pada pasar yang menyediakan fasilitas fisik yang serupa atau sebanding dengan produk rancangan. Pada perancangan fasilitas pembanding 1 terdapat keterbatasan sehingga penulis hanya menampilkan satu tabel antropometri saja yaitu data antropometri untuk perancangan rak sayur. Berikut adalah perancangan pada produk pembanding 1 . 
Tabel 2. Fasilitas Fisik Rancangan

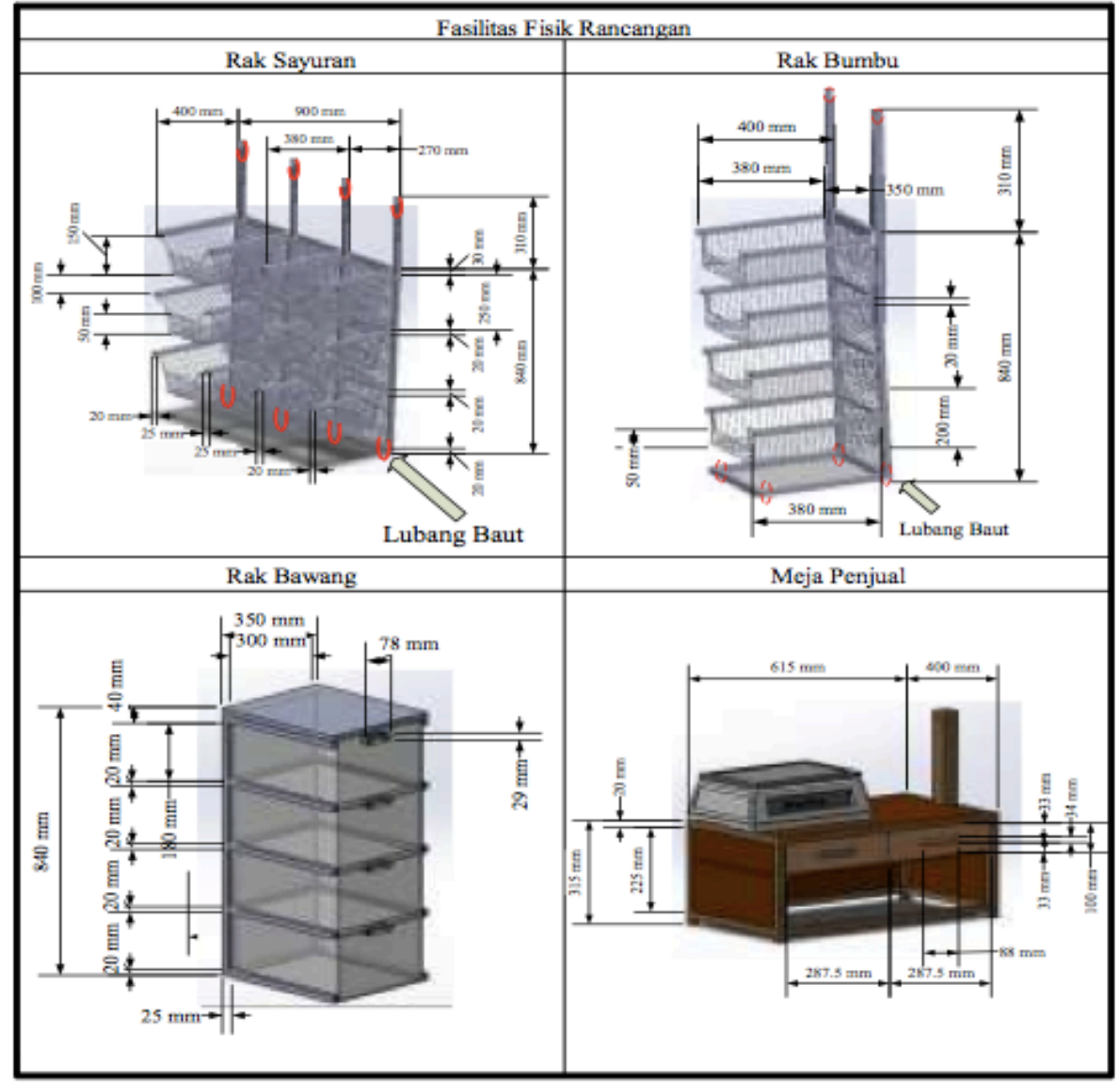

Tabel 3. Penentuan data antropometri dan acuan lainnya untuk perancangan rak sayur pembanding 1

\begin{tabular}{|c|c|c|c|c|c|c|c|c|c|c|}
\hline \multicolumn{2}{|c|}{ Dimensi } & Data Antropometri Atas Acuan Lainnya & Persentil & $\begin{array}{c}\text { Jenis } \\
\text { Kelamin }\end{array}$ & Ukuran (mm) & $\begin{array}{c}\text { Allowance } \\
(\mathrm{mm})\end{array}$ & $\begin{array}{l}\text { Ukuran } \\
\text { (mm) }\end{array}$ & $\begin{array}{c}\text { Ukuran } \\
\text { Yang } \\
\text { Disarankan } \\
\text { (mm) }\end{array}$ & $\begin{array}{c}\text { Ukuran } \\
\text { Permbanding 1 } \\
\text { (mm) }\end{array}$ & $\begin{array}{c}\text { Kesesuaian } \\
\text { Dengan } \\
\text { Data }\end{array}$ \\
\hline \multirow{2}{*}{$\begin{array}{l}\text { Panjang } \\
\text { Rak Sayur }\end{array}$} & Min & Lebar Bahu (bideltoid) & $5 \%$ & Wanita & - & - & 342 & \multirow{2}{*}{$342-1.400$} & \multirow{2}{*}{$600 \mathrm{~mm}$} & \multirow{2}{*}{ Sesuai } \\
\hline & $\operatorname{Max}$ & $\begin{array}{c}\text { Jarak Bentang dari Ujung Jari Tangan } \\
\text { Kiri ke Kanan } \\
\end{array}$ & $5 \%$ & Wanita & $\cdot$ & $\cdot$ & 1.400 & & & \\
\hline \multirow{2}{*}{$\begin{array}{c}\text { Lebar Rak } \\
\text { Sayur }\end{array}$} & Min & Dimensi Sayur Maksimun Yang Dijual & . & $\cdot$ & - & - & 200 & \multirow[b]{2}{*}{$200-610$} & \multirow[b]{2}{*}{$350 \mathrm{~mm}$} & \multirow[b]{2}{*}{ Sesuai } \\
\hline & $\operatorname{Max}$ & $\begin{array}{c}\text { Jarak Genggaman Tangan (grip) ke } \\
\text { Punggung pada Posisi Tangan ke Depan } \\
\text { (horisontal) } \\
\end{array}$ & $5 \%$ & Wanita & $\cdot$ & $\cdot$ & 610 & & & \\
\hline \multirow{2}{*}{$\begin{array}{c}\text { Tinggi Rak } \\
\text { Sayur }\end{array}$} & Min & $\begin{array}{c}\text { Tinggi Mata Berdiri - Tinggi Bak Kabin } \\
\text { Dari Tanah } \\
\end{array}$ & $50 \%$ & Wanita & $\begin{array}{c}1.446-700= \\
746\end{array}$ & - & 746 & \multirow{2}{*}{$746-842$} & \multirow{2}{*}{$1.000 \mathrm{~mm}$} & \multirow{2}{*}{$\begin{array}{l}\text { Tidak } \\
\text { Sesuai }\end{array}$} \\
\hline & $\operatorname{Max}$ & $\begin{array}{c}\text { Tinggi Mata Berdiri - Tinggi Bak Kabin } \\
\text { Dari Tanah }\end{array}$ & $95 \%$ & Wanita & $\begin{array}{c}1.542-700= \\
842\end{array}$ & $\cdot$ & 842 & & & \\
\hline \multirow{2}{*}{$\begin{array}{c}\text { Panjang } \\
\text { Keranjang } \\
\text { Di Dalam } \\
\text { Rak }\end{array}$} & Min & Dimensi Sayur Maksimun Yang Dijual & $\cdot$ & $\cdot$ & $\cdot$ & $\cdot$ & 200 & \multirow{2}{*}{$200-1.400$} & \multirow{2}{*}{$300 \mathrm{~mm}$} & \multirow{2}{*}{ Sesuai } \\
\hline & $\operatorname{Max}$ & $\begin{array}{c}\text { Jarak Bentang dari Ujung Jari Tangan } \\
\text { Kiri ke Kanan } \\
\end{array}$ & $5 \%$ & Wanita & $\cdot$ & $\cdot$ & 1.400 & & & \\
\hline \multirow{2}{*}{$\begin{array}{c}\text { Lebar } \\
\text { Keranjang } \\
\text { Di Dalam } \\
\text { Rak }\end{array}$} & Min & Dimensi Sayur Maksimun Yang Dijual & $\cdot$ & $\cdot$ & $\cdot$ & $\cdot$ & 200 & \multirow[b]{2}{*}{$200-610$} & \multirow[b]{2}{*}{$350 \mathrm{~mm}$} & \multirow[b]{2}{*}{ Sesuai } \\
\hline & $\operatorname{Max}$ & $\begin{array}{c}\text { Jarak Genggaman Tangan (grip) ke } \\
\text { Punggung pada Posisi Tangan ke Depan } \\
\text { (horisontal) }\end{array}$ & $5 \%$ & Wanita & $\cdot$ & $\cdot$ & 610 & & & \\
\hline \multirow{2}{*}{$\begin{array}{c}\text { Tinggi } \\
\text { Keranjang } \\
\text { Di Dalam } \\
\text { Rak } \\
\end{array}$} & Min & Dimensi Sayur Maksimun Yang Dijual & $\cdot$ & $\cdot$ & $\cdot$ & $\cdot$ & 150 & \multirow{2}{*}{$150-281$} & \multirow{2}{*}{$\begin{array}{l}\text { Tidak ada } \\
\text { informasi }\end{array}$} & \multirow{2}{*}{$\cdot$} \\
\hline & $\operatorname{Max}$ & Max Tinggi Rak Sayur x 1/3 & $\cdot$ & $\cdot$ & $\begin{array}{c}840 \times 1 / 3= \\
281\end{array}$ & $\cdot$ & 281 & & & \\
\hline $\begin{array}{l}\text { Modifikasi } \\
\text { Tinggi } \\
\text { Tiang } \\
\text { Penyangga }\end{array}$ & \begin{tabular}{|c|} 
Min \\
Max
\end{tabular} & $\begin{array}{c}\text { Tinggi Atap - Tinggi Rak - Ground } \\
\text { Clearence }\end{array}$ & $\cdot$ & $\cdot$ & $\begin{array}{c}1.850-1.000- \\
700=150\end{array}$ & - & 150 & 150 & $150 \mathrm{~mm}$ & $\cdot$ \\
\hline
\end{tabular}


Pada perancangan rak bumbu pembanding 1, ukuran yang didapat adalah $600 \mathrm{~mm}$ untuk panjang, $300 \mathrm{~mm}$ untuk lebar, $850 \mathrm{~mm}$ untuk tinggi, $600 \mathrm{~mm}$ untuk panjang keranjang, $300 \mathrm{~mm}$ untuk lebar keranjang, dan $170 \mathrm{~mm}$ untuk tinggi keranjang. Sedangkan ukuran pada rak bawang pembanding 1 adalah $500 \mathrm{~mm}$ untuk panjang rak, $400 \mathrm{~mm}$ untuk lebar, $900 \mathrm{~mm}$ untuk tinggi, $500 \mathrm{~mm}$ untuk panjang keranjang, $400 \mathrm{~mm}$ untuk lebar keranjang.

Tabel 4. Fasilitas fisik pembanding 1

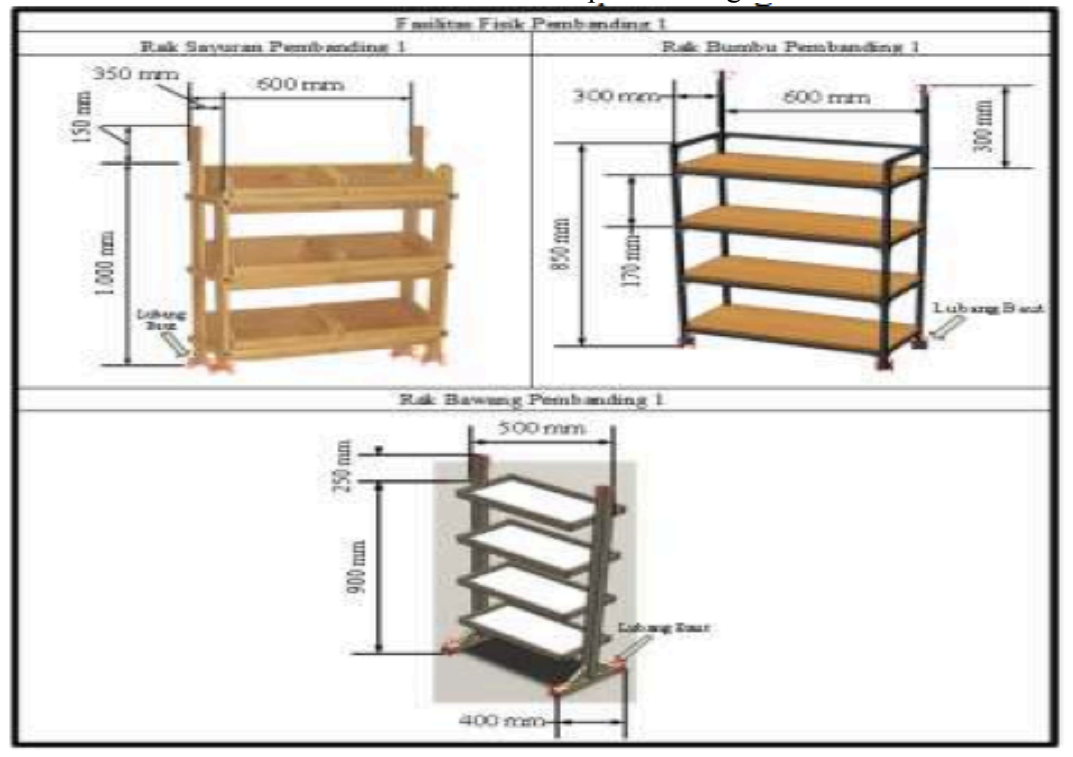

\section{Fasilitas Fisik Pembanding 2}

Perancangan fasilitas fisik pembanding didapatkan pada pasar yang menyediakan fasilitas fisik yang serupa atau sebanding dengan produk rancangan. Pada perancangan fasilitas pembanding 2 terdapat keterbatasan sehingga penulis hanya menampilkan satu tabel antropometri saja yaitu data antropometri untuk perancangan rak sayur. Berikut adalah perancangan pada produk pembanding.

Tabel 5. Penentuan data antropometri dan acuan lainnya untuk perancangan rak sayur pembanding 2

\begin{tabular}{|c|c|c|c|c|c|c|c|c|c|c|}
\hline \multicolumn{2}{|c|}{ Dimensi } & Data Antropometri Atas Acuan Lainnya & Persentil & $\begin{array}{c}\text { Jenis } \\
\text { Kelamin }\end{array}$ & Ukuran (mm) & $\begin{array}{c}\text { Allowance } \\
\text { (mm) }\end{array}$ & $\begin{array}{l}\text { Ukuran } \\
\text { (mm) }\end{array}$ & $\begin{array}{c}\text { Ukuran } \\
\text { Yang } \\
\text { Disarankan } \\
\text { (mm) }\end{array}$ & $\begin{array}{l}\text { Ukuran } \\
\text { Pembanding } 2 \\
\text { (mm) }\end{array}$ & $\begin{array}{c}\text { Kesesuaian } \\
\text { Dengan } \\
\text { Data }\end{array}$ \\
\hline \multirow{2}{*}{$\begin{array}{l}\text { Panjang } \\
\text { Rak Sayur }\end{array}$} & Min & Letbar Bahu (bideltroid) & $5 \%$ & Wanita & - & $\cdot$ & 342 & \multirow{2}{*}{$342-1.400$} & \multirow{2}{*}{$800 \mathrm{~mm}$} & \multirow{2}{*}{ Sesuai } \\
\hline & $\operatorname{Max}$ & \begin{tabular}{|c|} 
Jarak Bentang dari Ujung Jari Tangan \\
Kiri ke Kanan \\
\end{tabular} & $5 \%$ & Wanita & - & - & 1.400 & & & \\
\hline \multirow{2}{*}{$\begin{array}{c}\text { Lebar Rak } \\
\text { Sayur }\end{array}$} & Min & Dimensi Sayur Maksimun Yang Dijual & - & $\cdot$ & $\cdot$ & $\cdot$ & 200 & \multirow[b]{2}{*}{$200-610$} & \multirow[b]{2}{*}{$350 \mathrm{~mm}$} & \multirow[b]{2}{*}{ Sesuai } \\
\hline & $\operatorname{Max}$ & \begin{tabular}{|c|} 
Jarak Genggaman Tangan (grip) ke \\
Punggung peda Posisi Tangan ke Depan \\
(borisontal)
\end{tabular} & $5 \%$ & Wanita & $\cdot$ & - & 610 & & & \\
\hline \multirow{2}{*}{$\begin{array}{c}\text { Tinggi Rak } \\
\text { Sayur }\end{array}$} & Min & $\begin{array}{c}\text { Tinggi Mata Berdiri - Tinggi Bak Kabin } \\
\text { Dari Tanah } \\
\end{array}$ & $50 \%$ & Wanita & $\begin{array}{c}1.446-700= \\
746 \\
\end{array}$ & - & 746 & \multirow{2}{*}{$746-842$} & \multirow{2}{*}{$1000 \mathrm{~mm}$} & \multirow{2}{*}{$\begin{array}{l}\text { Tidak } \\
\text { Sesuai }\end{array}$} \\
\hline & $\operatorname{Max}$ & \begin{tabular}{|c|} 
Tinggi Mata Berdiri - Tinggi Bak Kabin \\
Dari Tanah
\end{tabular} & $95 \%$ & Wanita & $\begin{array}{c}1.542-700= \\
842 \\
\end{array}$ & - & 842 & & & \\
\hline \multirow{2}{*}{$\begin{array}{c}\text { Panjang } \\
\text { Keranjang } \\
\text { Di Dalam } \\
\text { Rak }\end{array}$} & Min & Dimensi Sayur Maksimun Yang Dijual & - & - & - & - & 200 & \multirow{2}{*}{$200-1.400$} & \multirow{2}{*}{$400 \mathrm{~mm}$} & \multirow{2}{*}{ Sesuai } \\
\hline & $\operatorname{Max}$ & \begin{tabular}{|c|} 
Jarak Bentang dari Ujung Jari Tangan \\
Kiri ke Kanan \\
\end{tabular} & $5 \%$ & Wanita & - & - & 1.400 & & & \\
\hline \multirow{2}{*}{$\begin{array}{c}\text { Leber } \\
\text { Keranjang } \\
\text { Di Dalam } \\
\text { Rak }\end{array}$} & Min & Dimensi Sayur Maksimun Yang Dijual & - & $\cdot$ & - & - & 200 & \multirow[b]{2}{*}{$200-610$} & \multirow[b]{2}{*}{$350 \mathrm{~mm}$} & \multirow[b]{2}{*}{ Sesuai } \\
\hline & $\operatorname{Max}$ & \begin{tabular}{|c|} 
Jarak Genggaman Tangan (grip) ke \\
Punggung pada Posisi Tangan ke Depan \\
(horisontal)
\end{tabular} & $5 \%$ & Wanita & $\cdot$ & - & 610 & & & \\
\hline \multirow{2}{*}{$\begin{array}{c}\text { Tinggi } \\
\text { Keranjang } \\
\text { Di Dalam } \\
\text { Rak }\end{array}$} & Min & Dimensi Sayur Maksimun Yang Dijual & $\cdot$ & - & $\cdot$ & $\cdot$ & 150 & \multirow{2}{*}{$150-281$} & \multirow{2}{*}{$\begin{array}{l}\text { Tidak ada } \\
\text { informasi }\end{array}$} & \multirow{2}{*}{ - } \\
\hline & $\operatorname{Max}$ & Max Tinggi Rak Sayur x 1/3 & $\cdot$ & - & $\begin{array}{c}840 \times 1 / 3= \\
281\end{array}$ & $\cdot$ & 281 & & & \\
\hline \multirow{2}{*}{$\begin{array}{l}\text { Modifikasi } \\
\text { Tinggi } \\
\text { Tiang } \\
\text { Penyangga }\end{array}$} & Min & \multirow{2}{*}{$\begin{array}{c}\text { Tinggi Atap - Tinggi Rak - Ground } \\
\text { Clearence }\end{array}$} & \multirow{2}{*}{ - } & \multirow{2}{*}{ - } & \multirow{2}{*}{$\begin{array}{c}1.850-1.000- \\
700=150\end{array}$} & \multirow{2}{*}{ - } & \multirow{2}{*}{150} & \multirow{2}{*}{150} & \multirow{2}{*}{$150 \mathrm{~mm}$} & \multirow{2}{*}{$\cdot$} \\
\hline & Max & & & & & & & & & \\
\hline
\end{tabular}


Tabel 6. Fasilitas fisik pembanding 2

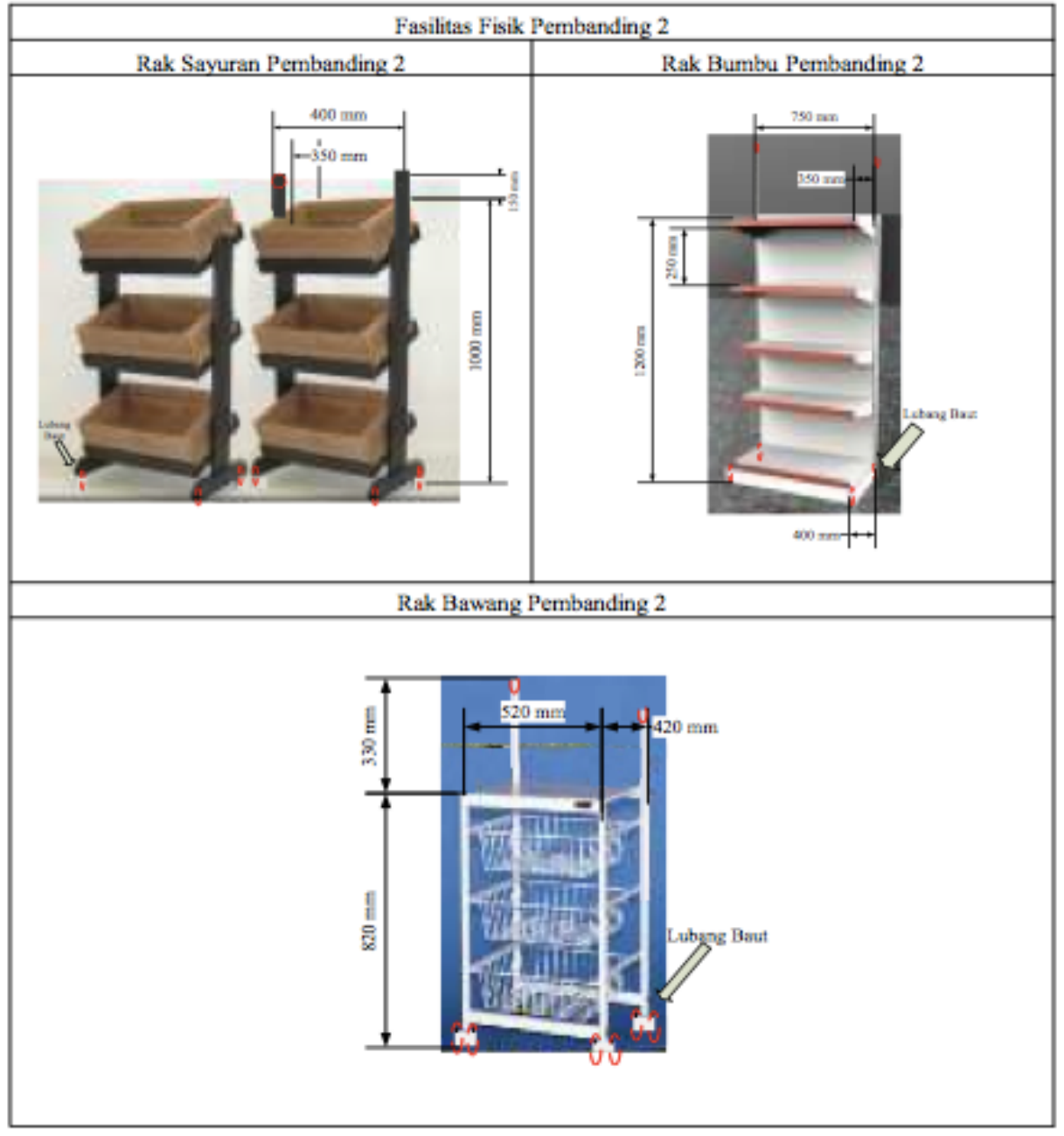

\section{Pemilihan Produk Fasilitas Fisik}

Pada rancangan fasilitas fisik pada penjual keliling, akan memiliki lima kriteria yang nantinya diambil satu alternatif terbaik berdasarkan nilai terbaik menggunakan metode concept scoring yaitu suatu metode untuk memutuskan konsep mana yang akan terus dikembangkan hingga akhirnya menjadi produk jadi dari beberapa konsep yang telah dimunculkan Ulrich, Karl T. \& Steven D. Eppinger (2016).

Adapun kriteria yang digunakan pada pemilihan alternatif tersebut yaitu: 1 . Kesesuaian dengan data antropometri. 2. Banyaknya jenis sayur yang dapat ditampung. 3. Kemudahaan dalam perawatan 4. Kemudahan dibersihkan 5. Keamanan Barang Berikut merupakan analisis dan pemilihan fasilitas fisik menggunakan metode concept scoring.

Tabel 7. Concept scoring rak sayuran

\begin{tabular}{|c|c|c|c|}
\hline \multirow{2}{*}{ Penilaian } & \multicolumn{3}{|c|}{ Nama Produk } \\
\cline { 2 - 4 } & Produk Rancangan & Produk Pembanding 1 & Produk Pembanding 2 \\
\hline $\begin{array}{c}\text { Kesesuaian Dengan Data } \\
\text { Antropometri }\end{array}$ & 3 & 2 & 2 \\
\hline $\begin{array}{c}\text { Banyak Jenis Sayur Yang } \\
\text { Ditampung }\end{array}$ & 3 & 2 & 1 \\
\hline Kemudahan Perawatan & 3 & 2 & 2 \\
\hline Kemudahan Dibersihkan & 3 & 3 & 3 \\
\hline Keamanan Barang & 3 & Rating & 3 \\
\hline & 15 & 12 & 11 \\
\hline Total Nilai & 1 & 2 & 3 \\
\hline Peringkat & \multicolumn{3}{|c|}{} \\
\hline
\end{tabular}


Tabel 8. Concept scoring rak bawang

\begin{tabular}{|c|c|c|c|}
\hline \multirow{2}{*}{ Penilaian } & \multicolumn{3}{|c|}{ Nama Produk } \\
\cline { 2 - 4 } & Produk Rancangan & Produk Pembanding 1 & Produk Pembanding 2 \\
\hline $\begin{array}{c}\text { Kesesuaian Dengan Data } \\
\text { Antropometri }\end{array}$ & 3 & 2 & 3 \\
\hline $\begin{array}{c}\text { Banyaknya Barang Yang } \\
\text { Dapat Ditampung }\end{array}$ & 1 & 2 & 3 \\
\hline Kemudahan Perawatan & 3 & 3 & 3 \\
\hline Mudah Dibersihkan & 3 & 1 & 1 \\
\hline Keamanan Barang & 3 & Rating & \\
\hline & 13 & 10 & 12 \\
\hline Total Nilai & 1 & 3 & 2 \\
\hline Peringkat & & & 2 \\
\hline
\end{tabular}

Tabel 9. Concept scoring rak bumbu

\begin{tabular}{|c|c|c|c|}
\hline \multirow{2}{*}{ Penilaian } & \multicolumn{3}{|c|}{ Nama Produk } \\
\cline { 2 - 4 } & Produk Rancangan & Produk Pembanding 1 & Produk Pembanding 2 \\
\hline $\begin{array}{c}\text { Kesesuaian Dengan Data } \\
\text { Antropometri }\end{array}$ & 3 & 2 & 3 \\
\hline $\begin{array}{c}\text { Banyaknya Barang Yang } \\
\text { Dapat Ditampung }\end{array}$ & 3 & 2 & 2 \\
\hline Kemudahan Perawatan & 3 & 3 & 3 \\
\hline Mudah Dibersihkan & 3 & 2 & 3 \\
\hline Keamanan Barang & 3 & Rating & 1 \\
\hline & 15 & 11 & 12 \\
\hline Total Nilai & 1 & 2 & 2 \\
\hline Peringkat & & & 2 \\
\hline
\end{tabular}

\section{Layout Fasiltas Fisik}

\section{Usulan dan Pemilihan Fasilitas Fisik}

Penyusunan tata letak fasilitas fisik supaya optimal maka akan ada tiga alternatif yang diusulkan yaitu alternatif 1 , alternative 2, dan alternatif 3 .
Layout Alternatif 1

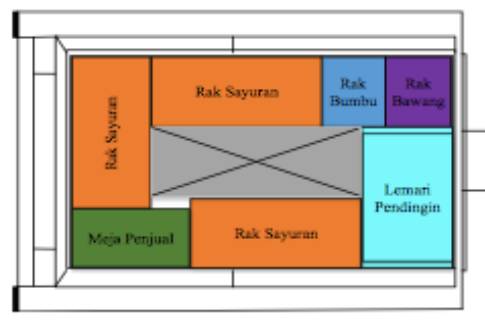

Layout Alternatif 2

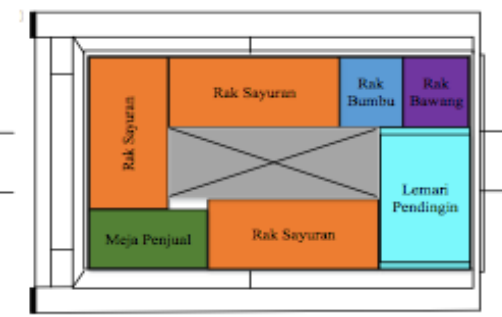

Gambar 1. Altenatif Layout

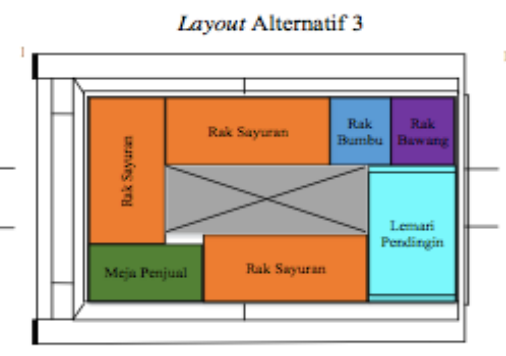

.

Tabel 10 Rangkuman tiap alternatif layout

\begin{tabular}{|c|l|l|l|}
\hline \multicolumn{3}{|c|}{ Rangkuman Perbandingan Tiap Alternatif } \\
\hline Fasilitas Fisik & \multicolumn{1}{|c|}{ Alternatif 1 } & \multicolumn{1}{|c|}{ Alternatif 2 } & \multicolumn{1}{|c|}{ Alternatif 3 } \\
\hline Rak Sayur & $\begin{array}{l}\text { Setiap rak sayur menghadap keluar } \\
\text { tetapi tidak berderet antara rak satu } \\
\text { dengan lainnya. }\end{array}$ & $\begin{array}{l}\text { Setiap rak sayur menghadap keluar dan } \\
\text { berderet antar masing-masing rak. }\end{array}$ & $\begin{array}{l}\text { Terdapat rak yang tidak menghadap } \\
\text { keluar. }\end{array}$ \\
\hline Lemari Pendingin & $\begin{array}{l}\text { Lemari pendingin berada di depan } \\
\text { kabin. }\end{array}$ & $\begin{array}{l}\text { Lemari pendingin berada di depan } \\
\text { kabin. }\end{array}$ & $\begin{array}{l}\text { Lemari pendingin berada di belakang } \\
\text { kabin dan memerlukan kabel yang } \\
\text { panjang. }\end{array}$ \\
\hline Rak Bumbu dan Rak Jaring & $\begin{array}{l}\text { Rak bumbu dan rak jaring } \\
\text { bersebelahan dan menghadap keluar } \\
\text { serta bersebelahan dengan rak sayuran } \\
\text { dan lemari pendingin. }\end{array}$ & $\begin{array}{l}\text { Rak bumbu dan rak jaring } \\
\text { bersebelahan dan menghadap keluar } \\
\text { serta bersebelahan dengan rak sayuran } \\
\text { dan lemari pendingin. }\end{array}$ & $\begin{array}{l}\text { Rak bumbu dan rak jaring } \\
\text { bersebelahan dan menghadap keluar } \\
\text { serta bersebelahan dengan meja } \\
\text { pedagang dan lemari pendingin. }\end{array}$ \\
\hline
\end{tabular}




\section{Pemilihan Fasilitas Fisik}

Berikut adalah kriteria-kriteria yang dibutuhkan oleh penjual dan pembeli yang akan digunakan dalam pemilihan layout fasilitas fisik. 1. Kemudahan penjual dalam menyimpan barang. 2. Mudah dilihat oleh penjual dan pembeli. 3. Kenyamanan pembeli dan penjual.

\begin{tabular}{|c|c|c|c|}
\hline \multicolumn{4}{|c|}{ Nama Layout } \\
\hline \multirow{2}{*}{ Penilaian } & Layout A & Layout B & Layout C \\
\hline & \multicolumn{3}{|c|}{ Rating (r) } \\
\hline $\begin{array}{l}\text { Kemudahan penjual dalam } \\
\text { menyimpan barang }\end{array}$ & 3 & 3 & 2 \\
\hline Mudah dilihat oleh konsumen. & 3 & 3 & 2 \\
\hline Kenyamanan konsumen & 2.5 & 3 & 2 \\
\hline Total Nilai & 8.5 & 9 & 6 \\
\hline Peringkat & 2 & 1 & 3 \\
\hline
\end{tabular}

Berdasarkan pemilihan altenatif layout, layout yang akan digunakan dalam proses perancangan adalah layout alternatif 2 dengan total nilai rating sebesar 9 .

\section{Penerapan 5S}

Penerapan metode 5S (Filip, 2015; Grahari, 2015) pada rancangan triseda, dimana Seiri yaitu melakukan pemilahan atau memisahkan barang, alat yang diperlukan dengan yang tidak diperlukan, Seiton dengan metata peralatan yang akan dipakai dengan dimasukan ke dalam wadah khusus dan menata barang yang dijual sesuai dengan fungsi masing-masing fasilitas fisik yang telah disediakan. Seiso dengan merancang setiap rak yang mudah untuk dibongkar dan tersedianya kain pembersih. Seiketsu yaitu penjual menjaga kondisi kerja yang rapih dan bersih dengan menyimpan kembali barang ke tempat semula, membersihkan barang yang telah selesai dipakai, dan membuang sampah ke tempatnya. Serta shitsuke adalah menyadarkan penjual untuk tetap berkomitmen agar tetap melakukan 4S yang telah dilakukan serta taat terhadap standar kerja yang telah ditetapkan.

\section{Keamanan Barang}

Pada perancangan fasilitas penjualan sayur mayur tidak lepas juga harus memperhatikan keamanan barang yang akan dibawa oleh triseda. Adapun poin analisis yang dibuat agar barang tetap aman saat dibawa. antara lain: 1. Menjaga barang dari hewan pengerat 2. Keamanan barang dari pencurian. 3. Menjaga kualitas makanan 4.
Keamanan dari wadah penyimpanan 5. Menjaga kebersihan makanan 6. Keamanan barang dari sinar matahari

\section{Perancangan Triseda}

Berikut merupakan rancangan triseda yang telah ditetapkan berdasarkan scoring concept yang telah terpilih yang menjadi rancangan akhir yang digunakan untuk menggantikan gerobak sayur keliling. Perancangan triseda memiliki panjang bak area dalam sebesar $2.000 \mathrm{~mm}$, lebar bak bagian dalam sebesar $1.300 \mathrm{~mm}$ sedangkan proses perancangan yang telah dilakukan menghasilkan panjang keseluruhan dari kendaraan yang digunakan adalah $3.000 \mathrm{~mm}$, lebar keseluruhan adalah $1.350 \mathrm{~mm}$, dan tinggi keseluruhan adalah $1.850 \mathrm{~mm}$. Pada bagian tengah bak kabin merupakan tempat penyimpanan sementara barang yang akan dijual.

Adapun dalam perancangannya adalah sebagai berikut:

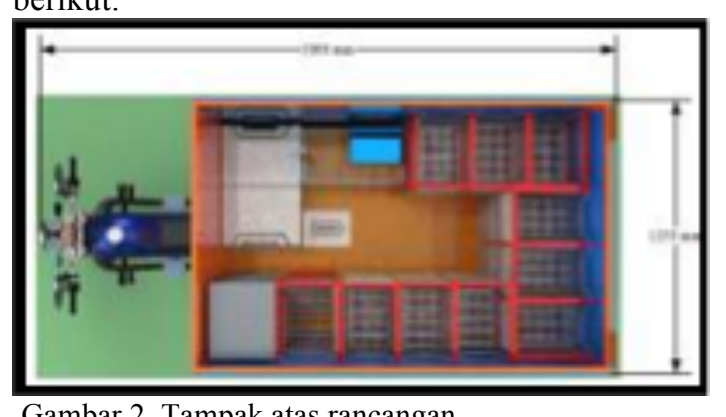

Gambar 2. Tampak atas rancangan 

dalam Bidang Teknik Industri

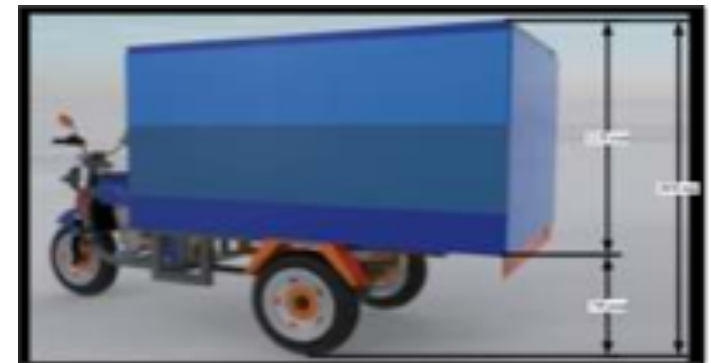

Gambar 3. Tampak samping rancangan

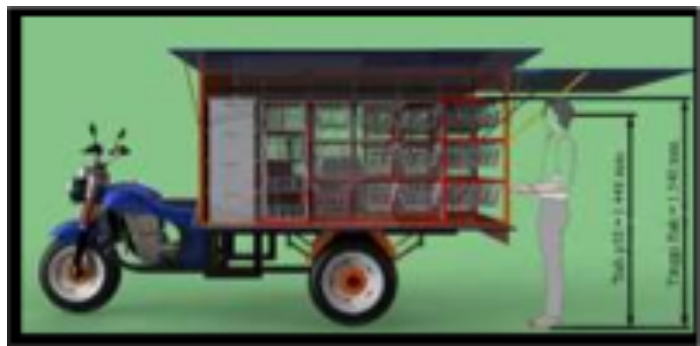

Gambar 4. Tampak samping kiri rancangan

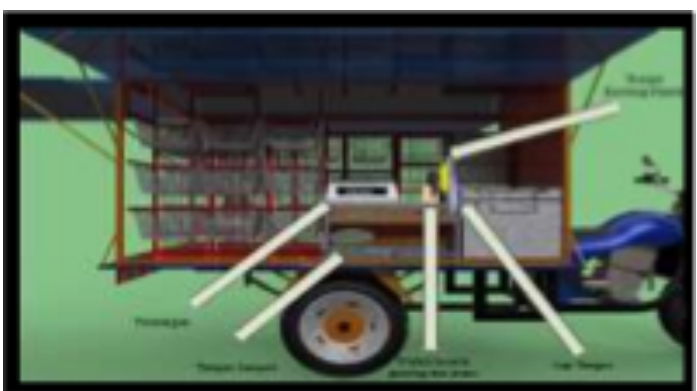

Gambar 5. Tampak samping kanan rancangan

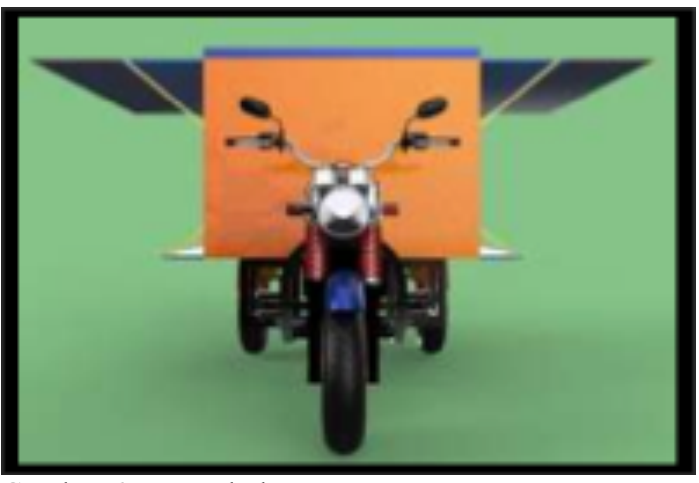

Gambar 6. Tampak depan rancangan

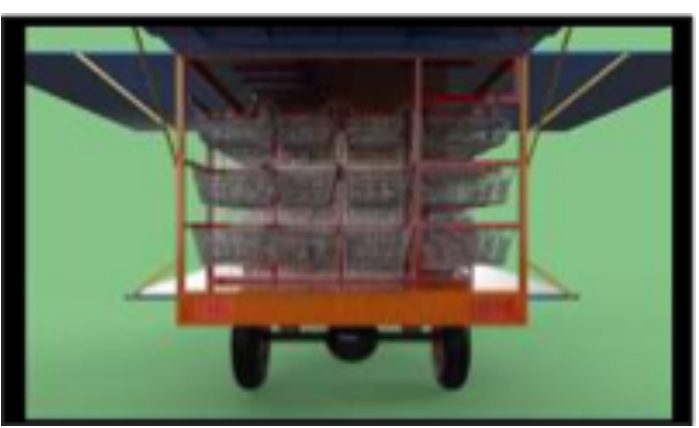

Gambar 7. Tampak belakang rancangan

\section{Mekanisme Penyimpanan Barang}

Triseda memiliki tempat penyimpanan yang berada pada tengah kabin kendaraan tujuannya adalah barang yang tidak tertampung pada rak dapat disimpan sementara pada tempat penyimpanan.

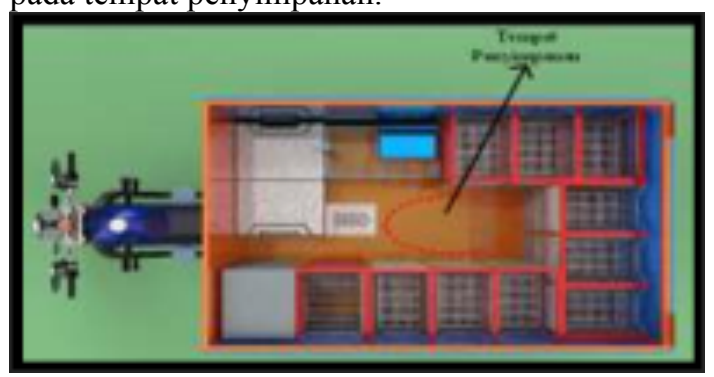

Gambar 8. Lokasi tempat penyimpanan

Mekanismenya adalah dengan menarik keluar rak sayur 1 sehingga bergeser seperti gambar 10

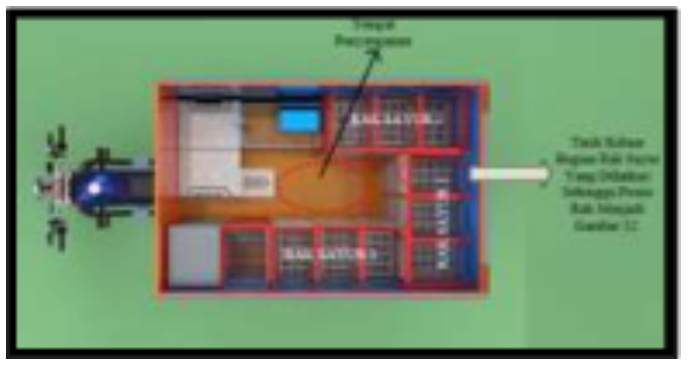

Gambar 9. Mekanisme menyimpan barang

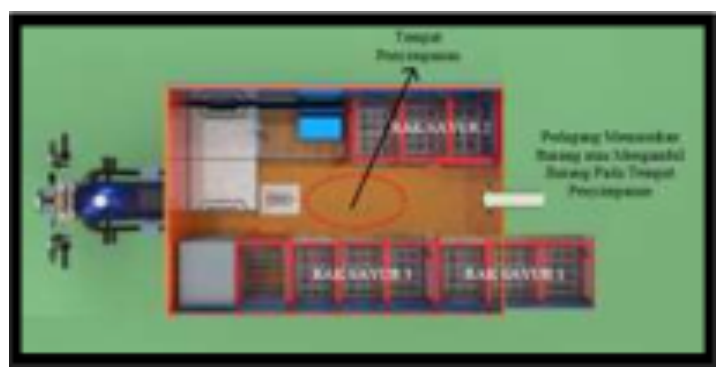

Gambar 10. Mekanisme menyimpan barang (4)

\section{Penutup Triseda}

Penutup triseda memiliki 2 mode, yaitu mode 1 yaitu bak yang memiliki ukuran $425 \mathrm{~mm}$ dan mode 2 yaitu bak dengan penutup $850 \mathrm{~mm}$. Mode 1 digunakan saat kondisi jalan yang sempit supaya diharapkan tidak menggangu pengguna jalan lainnya.

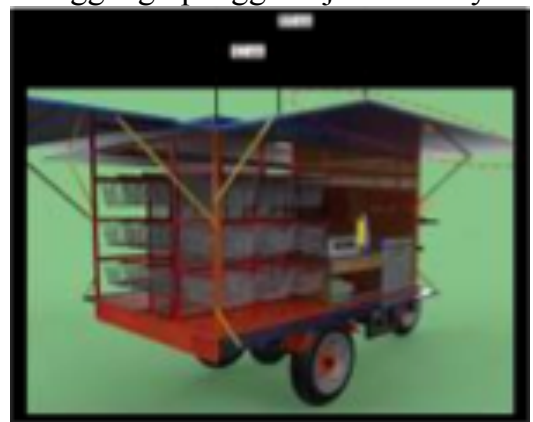

Gambar 11. Perancangan Triseda (Melebarkan Penutup Bak) 


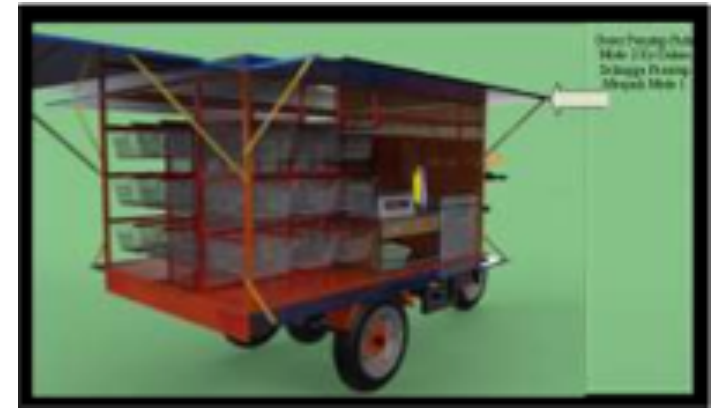

Gambar 12 Peracangan Triseda (Melebarkan Penutup Bak) (2)

Evaluasi terhadap perancangan produk ini hanya berdasarkan analisis poin concept scoring dan poin keamanan barang yang telah dibahas sebelumnya. Seperti halnya dalam perancangan ini sudah memperhatikan data anthropometri seperti yang di visualisasikan dalam gambar 4, sehingga pelanggan menjadi mudah, dan nyaman dalam mengambil barang. Sedangkan dari faktor keamanan seperti bahan yang digunakan pada rak bawang, wadah penyimpanan sudah dapat mencegah dari hewan pengerat yang masuk, bau amis, sinar matahari, dan kesegaran.

\section{Kesimpulan}

Perancangan fasilitas fisik yang dirancang adalah meliputi rak sayuran, rak bumbu, rak bawang, dan meja penjual. Pada layout dibuat berdasarkan dimensi dari kendaraan motor triseda yang digunakan yang merupakan penataan fasilitas fisik yang digunakan untuk menunjang proses penjualan yang dilakukan oleh penjual sayur keliling. Dalam perancangan layout terdapat tiga alternatif dan terpilih alternatif dua adalah alternatif terbaik. Penerapan metode $5 \mathrm{~S}$ pada rancangan triseda dimana Seiri yaitu melakukan pemilahan atau memisahkan barang, alat yang diperlukan dengan yang tidak diperlukan, Seiton dengan metata peralatan yang akan dipakai dengan dimasukan ke dalam wadah khusus dan menata barang yang dijual sesuai dengan fungsi masingmasing fasilitas fisik yang telah disediakan.
Seiso dengan merancang setiap rak yang mudah untuk dibongkar dan tersedianya kain pembersih. Seiketsu yaitu penjual menjaga kondisi kerja yang rapih dan bersih dengan menyimpan kembali barang ke tempat semula, membersihkan barang yang telah selesai dipakai, dan membuang, sampah ke tempatnya. Serta shitsuke adalah menyadarkan penjual untuk tetap berkomitmen agar tetap melakukan 4S yang telah dilakukan serta taat terhadap standar kerja yang telah ditetapkan.

\section{Saran}

Mengembangkan penelitian perancangan motor roda tiga sebagai moda untuk menjual sayur mayur keliling yang menggantikan gerobak sayur keliling agar lebih baik lagi dari yang telah dirancang sekarang.

\section{Daftar Pustaka}

Nurmianto, Eko (2004). Ergonomi: Konsep Dasar dan Aplikasinya. Edisi pertama. Surabaya: Penerbit Guna Widya.

Ginting, Rosnani (2010). Perancangan Produk. Yogyakarta: Graha Ilmu.

Effendi, S. (2012). Teknologi dan Pengawetan Pangan. Bandung: CV Alfabeta.

Grahari, R. S., Dangle, P. \& Chandratre, K. V (2015). Implementation of $5 S$ Methodology in The Small Scale Industry: A Case Study. International Journal of Scientific \& Technology Research

Filip,F.,\&Marascu-Klein,V.(2015).The5S Lean Method as a $T$ ool of Industrial Management Performances. IOP Conference Series: Materials Science and Engineering.

Ulrich,KarlT.\&StevenD.Eppinger(2016).

Product Design and Development. McGrawHill, New York. 